\title{
MONITORING OF THE GROUND FISSURE ACTIVITY WITHIN YUNCHENG BASIN BY TIME SERIES INSAR
}

\author{
F. Zhang ${ }^{1}$, C. S. Yang ${ }^{1, *}$, C. Y. Zhao ${ }^{1}$, R. C. Liu $^{2}$ \\ ${ }^{1}$ College of Geology Engineering and Geomatics, Chang'an University, Xi'an, Shaanxi province, 710054, China, \\ 18792574080@163.com; ycsgps@163.com; zhaochaoying@163.com \\ ${ }^{2}$ Earthquake Administration of Shanxi Province, Taiyuan, Shanxi Province, 030021, China, \\ wavelet1982@163.com
}

Commission III, WG III/3

KEY WORDS: Yuncheng Basin, Ground fissures, StaMPS technology, Ground subsidence, Faults, Ground water

\begin{abstract}
:
Yuncheng area is one of the most extensive distributions of ground fissures in Shanxi basin, especially in Yanhu District of Yuncheng, the disaster of ground fissures and ground subsidence are the most serious. According to previous studies, the development and distribution of the ground fissures in this area are mainly controlled by the underlying active faults. In order to provide a better understanding of the formation mechanism, the deformation of ground fissures and its surrounding environment should be taken into consideration. In this paper, PS-InSAR technology was employed to assess the time-series ground deformation of Yuncheng ground fissures and its surrounding area with X-band TerraSAR images from 2013 to 2015. The interaction between ground fissures activity and land subsidence, groundwater, precipitation and surrounding faults will be discussed.
\end{abstract}

\section{INTRODUCTION}

Ground fissure is a kind of crack on the surface under the action of natural factors (crustal activity, groundwater effect, etc.) and human activities (such as pumping, watering and excavation). In recent years, under the combined action of dynamic geological geology and human engineering activities, the scale and frequency of ground fissure has gradually increased, causing unpredictable damage to the natural environment and building structure. Therefore, to carry out ground fissure deformation monitoring and study of its activity are effective means of reduction and prevention for disaster.

Yuncheng Basin is located at the southwestern of the Shanxi Basin, with Emei Platform fault in the north, Zhongtiao Mountain in the east and south, and across the the Yellow River and Weihe Basin in the west. The total area is about $600 \mathrm{~m}^{2}$. The ground fissures in Fenwei basin are widely distributed. Yuncheng area is one of the most extensive distributions of ground fissures in Shanxi basin, especially in Yanhu District, the disasters of ground fissure and ground subsidence are very serious. From the perspective of the whole area, the ground fissures are mainly divided into banpo cracks, Ronghe-Liwang cracks and Xuedian cracks. Among them, Banpo ground fissure was monitored in this paper. Banpo ground fissure is developed on the southern side of Mingtiaogang fault, starting from the Shangwang and passing through Banpo, Wangrong and Wucao. It basically extends along the boundary line between the Mingtiaogang fault and the Qinglong River valley. The length of the fissure is about 10 $\mathrm{km}$. The section of the ground fissure is wedge-shaped, and the wall of fissure is curved and rough, showing the characteristics of tension and deformation. From its formation to the present, it still shows strong activity characteristic, and it is particularly evident during the rainy season or the period of agricultural irrigation. (The damage to the farmland caused by ground fissures is quite serious. The banpo ground fissure is repeatedly destroyed by several times, and the originally leveled farmland is damaged and become gully). In order to provide a better understanding of the formation mechanism, the deformation of the ground fissure and its surrounding environment should be taken into consideration.

There are various opinions on the causes of ground fissures in the Shanxi Basin. Most of them agree with the combined effects of tectonic factors and non-tectonic factors. Some people think that the causes of ground fissures in the Shanxi Basin are summarized as three types: Structure + Groundwater overdraft, structure + Loess collapse and simple loess collapse. The characteristics of tectonic origin of the ground fissures in the Yuncheng Basin are obvious. The development of ground fissures is associated with regional tectonic activity. The new tectonic activity is the dominant factor in the formation and development of ground fissures, and the loess collapse and groundwater overdraft are important inducing factors that induce ground fissures to appear on the surface or intensify the scale of other surface deformations.

Interferometric Synthetic Aperture Radar (InSAR) is a potential new remote sensing technology developed in the past 20 years. It has the advantages of all-weather, large-range, and highprecision monitoring of surface deformation. It has been applied in many geoscientific studies, but ground fissure monitoring is still in the exploration and practice stage. In view of this, in this paper, the persistent scatterer (PS)-InSAR algorithm proposed by Hooper in 2004 was used to monitor and analyze the land subsidence and ground fissure activities in Yuncheng area of Shanxi Province using the X-band TerraSAR images, so as to provide a basis for effective disaster reduction and avoidance.

\section{STAMPS TECHNOLOGY}

\subsection{Technology Principle}

Traditional D-InSAR is subject to various errors in the deformation measurement of the region, including orbit error,

\footnotetext{
* Corresponding author
} 
DEM error, decoherence influence, atmospheric delay error, phase unwrapping error, etc. . However, the main constraint of D-InSAR application deformation monitoring comes from the decoherence and atmospheric effects. Therefore, this has become the research to focus on improving the accuracy and reliability. In 2000, Ferretti et al. first proposed the PS-InSAR method and used 34 ERS SAR images to monitor the deformation of landslides in Ancona, Italy.

The core idea of the PS-InSAR method is to use a plurality of SAR images acquired in the same area within a certain time period to identify ground targets with strong reflection characteristics and stable scattering characteristics (that is the permanent scatterer), and then establish a phase model, according to the phase model for time series analysis, to separate the DEM error, atmospheric delay information and other errors and deformation information.

PS-InSAR technology can overcome the effects of atmospheric effects, temporal and spatial disassociation in conventional DInSAR. Even in the absence of interference fringes, it is possible to acquire millimeter-level deformation monitoring accuracy using PS points with stable phase on time-series SAR images. In 2004, Hooper proposed the StaMPS algorithm and based on the characteristics of the phase. The method selects points with small amplitude and stable phase as the final PS points. The example verified that the method can still select enough PS points in areas that can not be processed by the conventional PS algorithm, which greatly expands the application scope of the PS technology. The basic principles of StaMPS technology is as follows.

In processing, one of the sequenced SAR images is first selected as a common main image, and this image needs to be satisfied the best correlation with other images as a whole. Then by statistically analyzing the relationship between amplitude stability and phase stability, the initial PS points are selected. The amplitude dispersion involved was given by Ferretti et al. in 2001 based on the standard deviation and mean of the amplitude of the SAR images:

$$
D_{A}=\frac{\sigma_{A}}{\mu_{A}}
$$

Where $D_{A}=$ amplitude dispersion

$\sigma_{A}=$ standard deviation

$\mu_{A}=$ mean of the amplitude

The phase components of each pixel are analyzed and the spatially correlated and non-correlated components are further decomposed. Then the criterion for the candidate PS points is obtained based on this criterion. The algorithm uses the amplitude deviation index as the detection threshold of the PS primary selection points. The interferometric phase at the initial detection points is all composed of various phase such as deformation phase, orbit residual error, terrain error and atmospheric delay phase.

$$
\psi_{\mathrm{int}, x, i}=W\left\{\phi_{\operatorname{def}, x, i}+\phi_{a t m, x, i}+\Delta \phi_{o r b, x, i}+\Delta \phi_{\theta, x, i}+\phi_{n, x, i}\right\}
$$

\footnotetext{
Where $\psi_{\text {int }, x, i}=$ interferometric phase $\phi_{\text {def }, x, i}=$ deformation phase
}

$$
\begin{aligned}
& \phi_{\mathrm{atm}, x, i}=\text { atmospheric delay phase } \\
& \Delta \phi_{\mathrm{orb}, x, i}=\text { orbit residual error } \\
& \Delta \phi_{\theta, x, i}=\text { terrain error } \\
& \phi_{\mathrm{n}, x, i}=\text { noise error }
\end{aligned}
$$

The deformation of each preliminary point has a high degree of correlation. Based on this assumption, combined with the resolution of the SAR image, adaptive filtering is used to sequentially find the first four spatially relevant parts within a certain correlation space window and eliminate, and simultaneously estimate and eliminate spatially non-correlated incident angle error. This will be an iterative step that estimates the phase noise value for each candidate pixel in every interferogram. After iterate and converge, the residual components are used to estimate the correlation coefficient of the PS candidate points.

$$
\gamma_{\mathrm{x}}=\frac{1}{N}\left|\sum_{i=0}^{N} \exp \left\{j\left(\psi_{\mathrm{int}, x, i}-\tilde{\psi}_{\mathrm{int}, x, i}-\Delta \hat{\phi}_{\theta, x, i}^{n c}\right)\right\}\right|
$$

Where $\gamma_{\mathrm{x}}$ is defined as an estimate of the decorrelation noise, which is a representation of variations in the residual phase at the PS candidate pixel. The inner consistency of residual phase for PS pixels is better than other pixels, which is reflected through relatively higher $\gamma_{\mathrm{x}}$ value.

Hooper et al. (2007) proposed that threshold is selected based on probability statistics, it is considered that non-PS points also have a certain probability of having a higher value. Therefore, it is necessary to set the acceptable probability of non-PS points to be less than a reasonable threshold as a statistical criterion. Its purpose is to preserve the true PS points maximally. The expression of the probability that an acceptable PS point is selected by mistake is shown by equation (4):

$$
\frac{\left(1-\alpha\left(\hat{D}_{A, \mathrm{x}}\right)\right) \int_{\gamma}^{1} \text { thresh } \cdot p_{B}\left(\gamma_{X}\right) d_{\gamma x}}{\int_{\gamma}^{1} \text { thresh } \cdot p\left(\gamma_{x}, \hat{D}_{A, x}\right) d_{\gamma x}}=q
$$

where $\mathrm{q}$ is the maximum fraction of all the selected pixels that we will accept being non-PS pixels (false positives). The pixels with the $\gamma_{x}>\gamma^{\text {thresh }}$ would be picked up.

\subsection{Technology Process}

Stamps technology is mainly composed of four parts, as follows:

1. Interferogram Formation. Interferograms generated using Doris software. There are aspects of interferogram formation for PS processing that differ to conventional interferogram formation.

2. PS Identification. We use both amplitude and phase analysis to determine the PS probability for individual pixels. First we make an initial selection based only on amplitude analysis, then we refine the PS probability using phase analysis in an iterative process. Finally, we estimate the PS probability for those pixels not included in the initial selection. 
3. PS Selection. We select PS based on their PS probability, rejecting those that appear to be persistent only in certain interferograms and those that appear to be dominated by scatterers in adjacent PS pixels.

4. Displacement Estimation. Once selected, we isolate the signal due to deformation in the PS pixels. This involves "unwrapping" the phase values and subtracting estimates of the various nuisance terms.

The technique flow chart is as follows in figure 1, especially the selection of PS points.

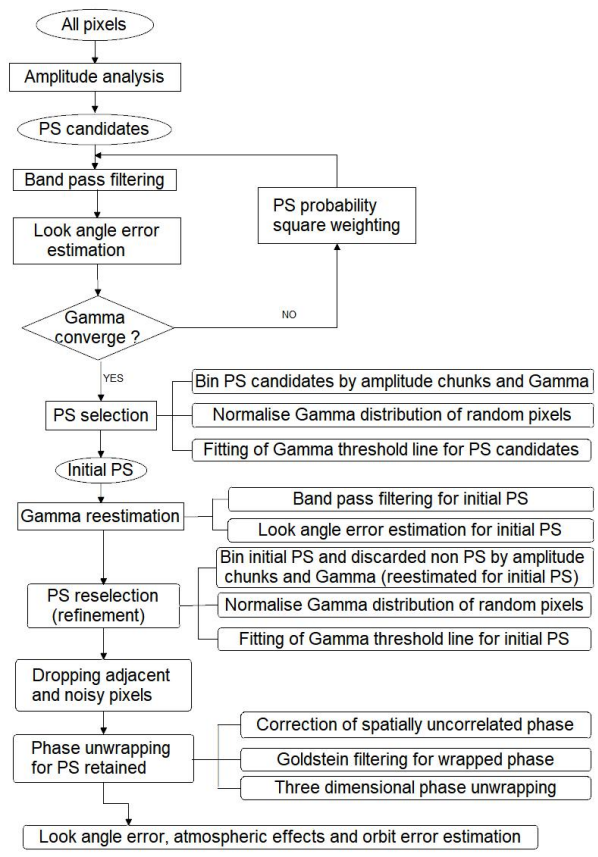

Figure 1. StaMPS technique flow chart

\section{EXPERIMENTAL AREA AND DATA}

The area studied in this paper is mainly the Banpo area in the Yuncheng Basin, as shown in Figure 3. This paper used 22 TerraSAR-X data spanning from April 2013 to May 2015. The DEM we used is SRTM30 data. First, consider the common effects of time baseline, space baseline, and Doppler center frequency to maximize the sum of coherence. Therefore, the data of 20140719 is selected as the main image. The following figure 2 shows the spatial baseline distribution.

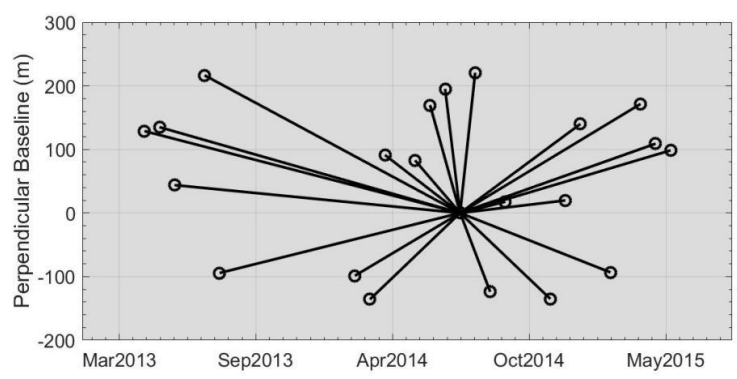

Figure 2. Baseline distribution of data

\section{RESULT AND ANALYSIS}

\subsection{Deformation Time Series Analysis}

The deformation time series of Yuncheng ground fissures and its surrounding area were obtained through StaMPS technology. As shown in the figure 3, the DEM data was shown as the background and the faults and the main researched ground fissure in the Yuncheng Basin were shown.

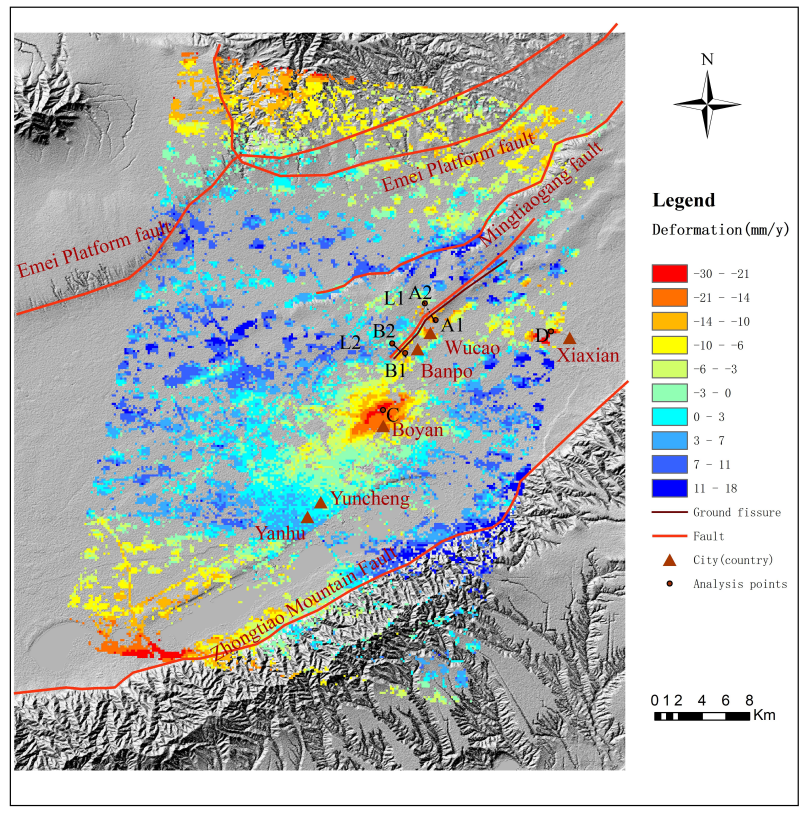

Figure 3. Deformation rate map

It can be clearly seen from the deformation rate map that the most serious deformation areas are mainly located in Boyuan Village and its surrounding areas in Yanhu District, and with this as the center, a very clear oval-shaped subsidence funnel was formed. In addition, a section line analysis was performed on the subsidence funnel, as shown in Figure 4, and the maximum annual rate deformation reached $25 \mathrm{~mm}$.

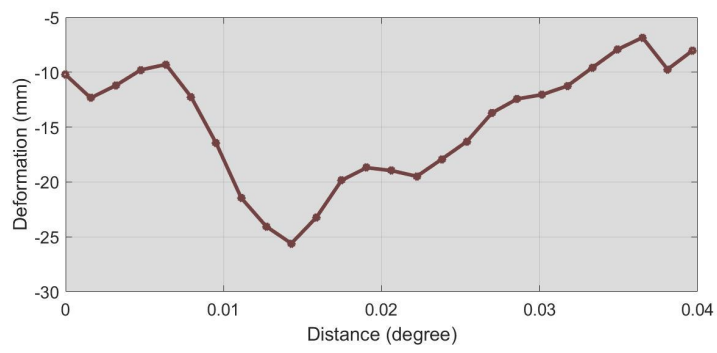

Figure 4. The profile of deformation area

In order to further analyze the subsidence in the area, several characteristic points in the main study area were extracted for analysis. First, a point located at the center area was extracted in the sedimentation funnel area for analysis. As shown in the figure 5 below, from 2013 to 2015 , at the point of the center of the subsidence, the maximum cumulative deformation reached about $30 \mathrm{~mm}$. 


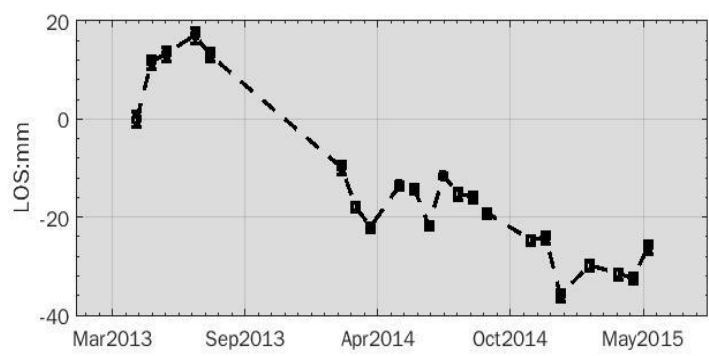

Figure 5. Deformation of point C

In addition, there is surface subsidence in Banpo ground fissure and Xiaxian area. It is shown that the deformation time series of characteristic point in Xiaxian area in figure 6. Land subsidence in Xiaxian area is more serious than Yanhu District, and the maximum cumulative deformation can reach nearly $60 \mathrm{~mm}$.

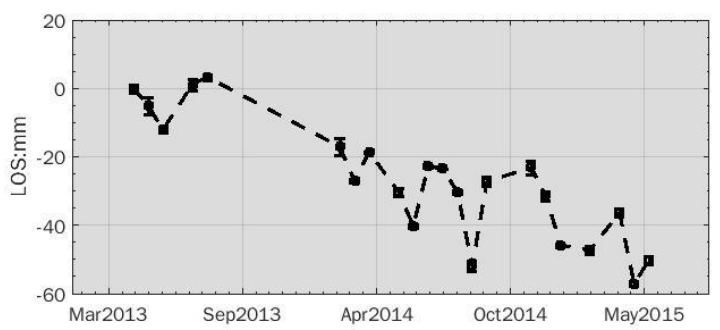

Fig 6. Deformation of point D

\subsection{Analysis of Ground Fissure}

There are multiple ground fissures in the study area, but this paper focuses on Banpo ground fissure. In order to further monitor the deformation characteristics of Banpo ground fissure, a pair of points were extracted on the two vertical lines along the ground fissure, and deformation time series analysis was performed.

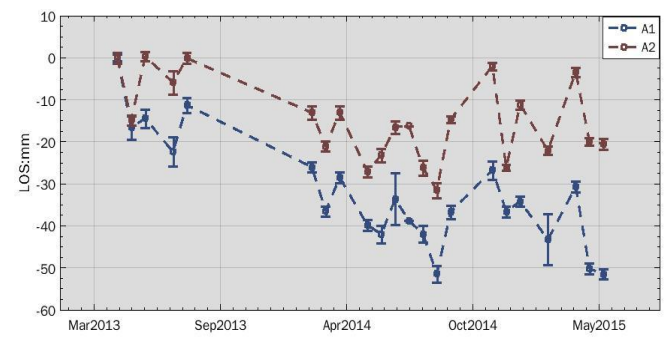

Figure 7. Deformation of a pair of points A1 and A2

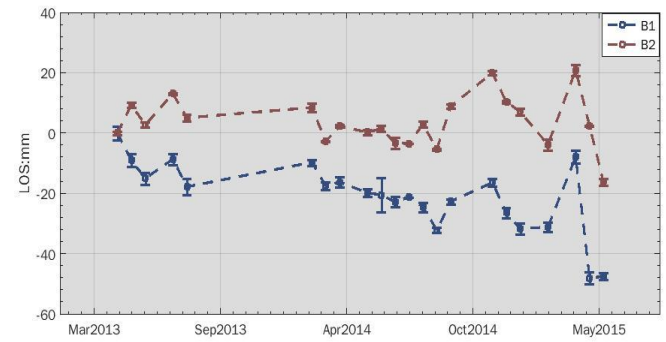

As shown in Figure 3, A1, A2 and B1, B2 are two pairs of points. The deformation time series of these two pairs of points showed a slow downward trend. As shown in Figure 7 and Figure 8, the two points of $\mathrm{A} 1$ and $\mathrm{B} 1$ are distributed on the south side of the ground fissure respectively, and the deformation is about $20 \mathrm{~mm}$. The two points of A2 and B2 are on the north side, and the deformation is greater than $40 \mathrm{~mm}$. The land on both sides of the ground fissure showed a slow decline, but there is a clear difference in deformation.

\subsection{Factors Analysis of Induced Banpo Ground Fissure}

By investigating the fault and Banpo ground fissure, it is found that the location and direction of the Banpo ground fissure are basically the same as the fault. It can be seen that the development and distribution of the ground fissure in this area are mainly controlled by the underlying active faults.

According to the survey, groundwater is over-exploited in multiple areas in the Yuncheng Basin.There are three severely over-exploited areas, include the study area. Overexploitation of the groundwater flow and infiltration of surface water create a large groundwater funnel area over a long period of time. Therefore, groundwater over-exploitation is the main factor for land subsidence and ground fissures in Yanhu District and Xiaxian. The groundwater level is shown in the past 15 years in figure 9.

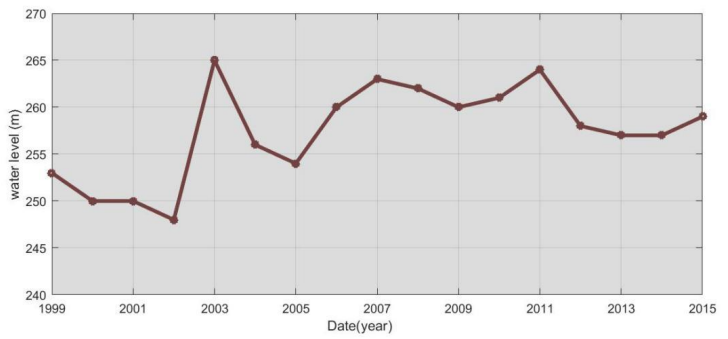

Figure 9. Change of water level in funnel center

\section{CONCLUSION}

The time-series ground deformation of Yuncheng ground fissure and its surrounding area were obtained during the period of 2013 to 2015 with X-band TerraSAR images. It was found that the major subsidence areas in the Yuncheng Basin were located in the east side of the Yanhu District and the west side of Xiaxian . The Banpo ground fissure is also in the process of development. And by investigating the distribution of ground fissure in the Yuncheng Basin and the over-exploitation of groundwater, the causes of some ground fissures have been proven. The new tectonic activity is the dominant factor in the formation and development of ground fissures, and groundwater overdraft and other external forces are important precipitating factors that induce ground fissures to appear on the surface or intensify the scale of other surface deformations.

There may be some errors in the result obtained by the StaMPS technique in this paper, but the monitoring of ground fissures is basically not affected. The next task is to remove these errors and make the result more accurate.

Figure 8. Deformation of a pair of points B1 and B2 


\section{ACKNOWLEDGEMENTS}

This research was supported by Shanxi Science and Technology Project (20140313023-1), National Natural Science Foundation of China (NSFC) (Nos. 41604015, 41731066, 41628401 and 41604001) and the Special Earthquake Research Project of China (No. 201508009).

\section{REFERENCES}

Ferretti, A., Prati, C., Rocca, F. (2000). Nonlinear subsidence rate estimation using permanent scatterers in differential sar interferometry. IEEE Transactions on Geoscience \& Remote Sensing, 38(5), 2202-2212.

Hooper, A., Segall, P., Zebker, H. A. (2007). Persistent scatterer insar for crustal deformation analysis, with application to volcán alcedo, galápagos. Journal of Geophysical Research Atmospheres, 112(B7).

Hooper, A. (2008). A multi-temporal insar method incorporating both persistent scatterer and small baseline approaches. Geophysical Research Letters, 35(16), 96-106.

Hooper, A., Bekaert, D., Spaans, K., Arikan, M. (1951). Recent advances in sar interferometry time series analysis for measuring crustal deformation. Tectonophysics, 514(1), 1-13.

Hooper, A., Zebker, H., Segall, P., Kampes, B. (2004). A new method for measuring deformation on volcanoes and other natural terrains using insar persistent scatterers. Geophysical Research Letters, 31(23), 1-5.

Li, H.J. (2016). Groundwater overdraft and its environmental impacts and countermeasures in Yuncheng City. Ground water, 38(5), 88-90.

Sun, H., Zhang, Q., Zhao, C. Y., Yang, C. S., Sun, Q., Chen, W. (2017). Monitoring land subsidence in the southern part of the lower liaohe plain, china with a multi-track ps-insar technique. Remote Sensing of Environment, 188, 73-84.

Samsonov, S., D'Oreye, N. (2012). Multidimensional timeseries analysis of ground deformation from multiple insar data sets applied to virunga volcanic province. Geophysical Journal International, 191(3), 1095-1108.

Xu, J.S., Zhuang, H.D., Tang, D.Q., Li, Z.C.. (2010) Characteristics and mechanism analysis of ground fissures in Yuncheng Basin. Journal of Geological Hazards and Environment Preservation, 21(2), 97-100.

Yao, L.. (2017). The status quo of Groundwater funnel area and analysis on its treatment measures in Yuncheng. Ground water, 39(3), 57-59.

Zhang, J., Zhang, Q., Qu, F.F.. (2012). SBAS-InSAR monitoring and sensitive GIS analysis of land subsidence in Yuncheng City. Shanghai Land \& Resources, 33(1), 58-61. 